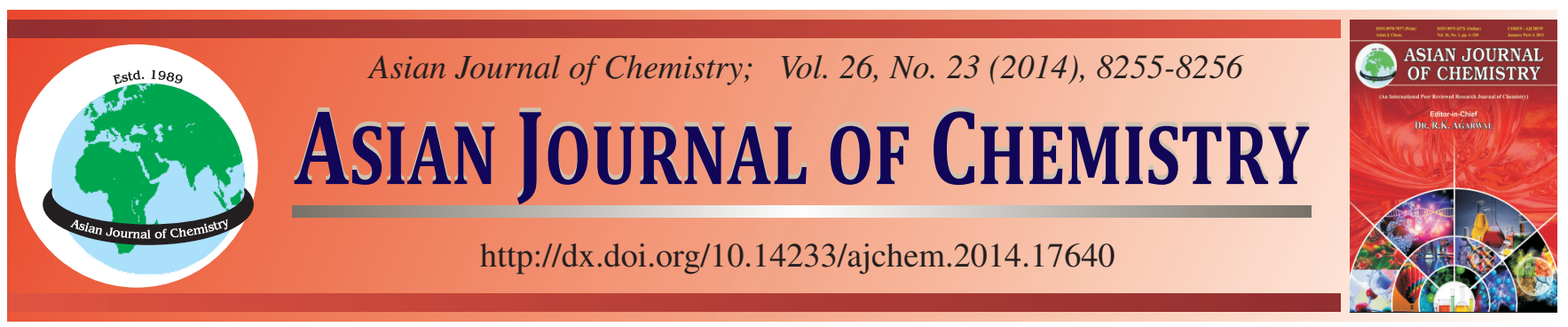

NOTE

\title{
Avarol Effectively Inhibits Bacillus cereus Growth
}

\author{
B. Pejin ${ }^{1, *}$, T. Kartali ${ }^{2}$, B. Stanimirovic ${ }^{3}$ and M. Karaman ${ }^{2}$
}

${ }^{1}$ University of Belgrade, Institute for Multidisciplinary Research - IMSI, Department of Life Sciences, Kneza Viseslava 1, 11030 Belgrade, Serbia ${ }^{2}$ University of Novi Sad, Faculty of Sciences, Department of Biology and Ecology, Trg Dositeja Obradovica 2, 21000 Novi Sad, Serbia ${ }^{3}$ Institute MOL Ltd, Nikole Tesle 15, 22300 Stara Pazova, Serbia

*Corresponding author: E-mail: brspjn@gmail.com; boris.pejin@imsi.rs

Received: 21 March 2014;

Accepted: 15 April 2014;

Published online: 15 November 2014;

AJC-16338

This work extends in vitro screening of antibacterial activity of avarol on four selected pathogenic bacteria associated with psoriasis (Bacillus cereus, Clostridium sporogenes, Enterococcus faecalis and Staphylococcus aureus). Avarol exhibited a moderate activity with minimum inhibitory and minimum bactericidal concentrations ranged from $0.78-1.56$ and 3.12-18.75 $\mu \mathrm{g} / \mathrm{mL}$, respectively. It proved to be more effective against $B$. cereus in comparison to the both positive controls applied, gentamycin and ampicillin. According to the experimental data, this marine natural product may inspire development of new antibiotics with an enhanced therapeutic index, at first place those targeting B. cereus.

Keywords: Porifera, Dysidea avara, Marine natural product, Antibacterial activity, Psoriasis.

Sponges are sessile organisms with a specific chemical defense of great interest for the natural product chemists. Indeed, their terpenoid quinones and hydroquinones have attracted the most attention ${ }^{1}$.

Avarol, a marine sesquiterpenoid hydroquinone possessing a rearranged drimane skeleton, is the main secondary metabolite of the Mediterranean sponge Dysidea avara Schmidt ${ }^{2,3}$. Pharmacological properties of this natural product include antibacterial, antifungal and antiviral activities ${ }^{4}$. It has shown to be active against a variety of Gram-positive bacterial and some fungal species. On the other hand, no antibacterial activity has been found for Gram-negative bacteria ${ }^{5-7}$.

Avarol exhibits antipsoriatic activity as well ${ }^{8}$. Indeed, recent studies performed in human keratinocytes showed that avarol decreased the production of skin-derived antileukoproteinase (SKALP/Elafin) determined as index of psoriatic keratinocyte differentiation, without affecting cell proliferation. It is supposed that observed biological activity is partially mediated by the downregulation of TNF- $\alpha$ and NF- $\kappa$ B in psoriatic skin'. Psoriasis is a common skin disease characterized by epidermal hyperplasia, inflammation in dermis and epidermis and leukocyte infiltration ${ }^{10}$. However, its pathogenesis still remains unclear. Pathogenic organisms that have been associated with psoriasis include Bacillus cereus, Clostridium sp., Enterococcus faecalis and Staphylococcus aureus $^{11,12}$. Anthralin is among the most widely used drugs in the treatment of psoriasis. However, its clinical efficacy is limited by the side-effects of irritation and staining of the uninvolved skin $^{13}$.

The low toxicity in male mice (lethal dose for $10 \%$ of the mice kill is $111 \mathrm{mg}$ ) and no side effects in men (at the dose of $3 \mathrm{mg} / \mathrm{kg})^{14,15}$, prompted us to extand in vitro antibacterial screening of avarol related to psoriasis. The screening has included four Gram-positive bacteria, namely Bacillus cereus ATCC 11778, Clostridium sporogenes ATCC 19404, Enterococcus faecalis ATCC 19433 and Staphylococcus aureus ATCC 25923. Avarol was isolated from the sponge D. avara, collected in the Bay of Kotor (Kotor, Montenegro) as previously reported ${ }^{2,3}$, while its antibacterial activity was evaluated in vitro by a microdilution method ${ }^{16}$.

This marine natural product exhibited good activity against all bacteria tested with minimum inhibitory (MIC) and bactericidal (MBC) concentrations ranged from 0.78-1.56 and $3.12-18.75 \mu \mathrm{g} / \mathrm{mL}$, respectively (Table-1).

The most sensitive bacterium was B. cereus with MIC/ $\mathrm{MBC}$ values reached at 0.78 and $3.12 \mu \mathrm{g} / \mathrm{mL}$, respectively. In comparison, both positive controls used, gentamycin and ampicillin, were less effective towards this strain (MIC/MBC values $2.50 / 10.00 \mu \mathrm{g} / \mathrm{mL}$ and $2.00 / 4.00 \mu \mathrm{g} / \mathrm{mL}$, respectively). It's worth noting that avarol did show selectivity against the Gram-positive bacteria screened inhibiting B. cereus and $E$. faecalis in a bactericidal rather than in a bacteriostatic manner 
TABLE-1

MINIMUM INHIBITORY (MIC) AND BACTERICIDAL (MBC) CONCENTRATIONS OF AVAROL

\begin{tabular}{|c|c|c|c|}
\hline Bacteria & Avarol $^{* ¥}$ & Gentamycin $^{* \# ¥}$ & Ampicillin $^{* \# \#}$ \\
\hline Bacillus & $0.78 \pm 0.02$ & $2.50 \pm 0.03$ & $2.00 \pm 0.06$ \\
\hline cereus ATCC 11778 & $3.12 \pm 0.03$ & $10.00 \pm 0.02$ & $4.00 \pm 0.08$ \\
\hline Clostridium & $1.56 \pm 0.06$ & $2.50 \pm 0.02$ & $64.00 \pm 0.06$ \\
\hline sporogenes ATCC19404 & $18.75 \pm 0.03$ & $>20$ & $>128$ \\
\hline Enterococcus & $1.56 \pm 0.03$ & $5.00 \pm 0.06$ & $16.00 \pm 0.03$ \\
\hline faecalis ATCC 19433 & $6.25 \pm 0.06$ & $>20$ & $>128$ \\
\hline Staphylococcus & $1.56 \pm 0.08$ & $2.50 \pm 0.06$ & $8.00 \pm 0.06$ \\
\hline aureus ATCC 25923 & $12.50 \pm 0.06$ & $10.00 \pm 0.03$ & $>128$ \\
\hline
\end{tabular}

$(\mathrm{MBC} / \mathrm{MIC}=4)$. This study confirms avarol potential related to psoriasis and indicates the need for the antibacterial activity screening at in vivo conditions. Indeed, its chemical structure may inspire development of new and more effective antibiotics targeting $B$. cereus, the bacterium known to cause chronic skin infections that are difficult to eradicate.

\section{ACKNOWLEDGEMENTS}

This work was supported by the Ministry of Education, Science and Technological Development of the Republic of Serbia (Research grants Nos. 172053 and 172058). The authors gratefully acknowledge Prof. Dusan Sladic (University of Belgrade, Faculty of Chemistry, Department of Organic Chemistry) and Dr. Irena Novakovic (University of Belgrade, ICTM, Center of Chemistry) for providing the sample of avarol.

\section{REFERENCES}

1. D. Sladic and M.J. Gasic, Molecules, 11, 1 (2006).

2. L. Minale, R. Riccio and G. Sodano, Tetrahedron Lett., 15, 3401 (1974).

3. S. De Rosa, L. Minale, R. Riccio and G. Sodano, J. Chem. Soc., Perkin Trans. 1, 1408 (1976).
4. M.J. Gašic, J. Serb. Chem. Soc, 53, 229 (1988).

5. L. Cariello, L. Zanetti, V. Cuomo and F. Vanzanella, Comp. Biochem. Physiol. B, 71, 281 (1982).

6. G. Seibert, W. Raether, D. Dogovic, M.J. Gašic, R.K. Zahan and W.E. Müller, Zentralbl. Bakteriol. Mikrobiol. Hyg. A, 260, 379 (1985).

7. B. Pejin, C. Iodice, G. Tommonaro and S. De Rosa, J. Nat. Prod., 71, 1850 (2008).

8. M. Amigó, M.C. Terencio, M. Mitova, C. Iodice, M. Payá and S. De Rosa, J. Nat. Prod., 67, 1459 (2004).

9. M. Amigó, M. Payá, A. Braza-Boïls, S. De Rosa and M.C. Terencio, Life Sci., 82, 256 (2008).

10. P.F. Lizzul, A. Aphale, R. Malaviya, Y. Sun, S. Masud, V. Dombrovskiy and A.B. Gottlieb, J. Invest. Dermatol., 124, 1275 (2005).

11. M. Peslyak, Model of Pathogenesis of Psoriasis, Systemic Psoriatic Process, MYPE, Moscow, Part 1, pp. 84 (2012).

12. E.W. Rosenberg, P.W. Noah and R.B. Skinner Jr., J. Natl. Med. Assoc., 86, 305 (1994).

13. R. Parslew and P.S. Friedmann, J. Dermatol., 141, 469 (1999).

14. W.E.G. Müller, A. Maidhof, R.K. Zahn, H.C. Schröder, M.J. Gašic, D. Heidemann, A. Bernd, B. Kurelec, E. Eich and G. Seibert, Cancer Res., 45, 4822 (1985).

15. W.E.G. Müller, A. Sarin, Y. Kuchino, A. Dorn, G. Hess, K.-H. Meyer zum Büschenfelde, M. Rottmann and H.C. Schröder, in eds.: W. Vettermann and M. Schauzu, AIDS, Bundesministeriums für Forschung und Technologie, Bonn, p. 354 (1987).

16. M. Karaman, N. Mimica-Dukic, P. Knezevic, Z. Svircev and M. Matavuly, Int. J. Med. Mushrooms, 11, 269 (2009). 